\title{
Cyclic Lipopeptides of Bacillus amyloliquefaciens subsp. plantarum Colonizing the Lettuce Rhizosphere Enhance Plant Defense Responses Toward the Bottom Rot Pathogen Rhizoctonia solani
}

\author{
Soumitra Paul Chowdhury, ${ }^{1}$ Jenny Uhl, ${ }^{2}$ Rita Grosch, ${ }^{3}$ Sylvia Alquéres, ${ }^{1}$ Sabrina Pittroff, ${ }^{1}$ \\ Kristin Dietel, ${ }^{4}$ Philippe Schmitt-Kopplin, ${ }^{2,5}$ Rainer Borriss, ${ }^{4,6}$ and Anton Hartmann ${ }^{1}$ \\ ${ }^{1}$ Research Unit Microbe-Plant Interactions, Department Environmental Sciences, Helmholtz Zentrum Muenchen, German \\ Research Center for Environmental Health $(\mathrm{GmbH})$, Neuherberg, Germany; ${ }^{2}$ Research Unit Analytical Biogeochemistry, \\ Department Environmental Sciences, Helmholtz Zentrum Muenchen; ${ }^{3}$ Leibniz-Institute of Vegetable and Ornamental Crops, \\ D-14979 Großbeeren, Germany; ${ }^{4}$ ABiTEP GmbH, D-12489 Berlin, Germany; ${ }^{5}$ Technische Universitaet Muenchen, Chair of \\ Analytical Food Chemistry, Freising-Weihenstephan, Germany; and ${ }^{6}$ Fachgebiet Phytomedizin, Institut für Agrar-und \\ Gartenbauwissenschaften, Humboldt-Universität zu Berlin, Germany
}

Submitted 30 March 2015. Accepted 22 May 2015.

\begin{abstract}
The commercially available inoculant Bacillus amyloliquefaciens FZB42 is able to considerably reduce lettuce bottom rot caused by Rhizoctonia solani. To understand the interaction between FZB42 and $R$. solani in the rhizosphere of lettuce, we used an axenic system with lettuce bacterized with FZB42 and inoculated with $R$. solani. Confocal laser scanning microscopy showed that FZB42 could delay the initial establishment of $R$. solani on the plants. To show which secondary metabolites of FZB42 are produced under these in-situ conditions, we developed an ultra-high performance liquid chromatography coupled to time of flight mass spectrometry-based method and identified surfactin, fengycin, and bacillomycin $D$ in the lettuce rhizosphere. We hypothesized that lipopeptides and polyketides play a role in enhancing the plant defense responses in addition to the direct antagonistic effect toward $R$. solani and used a quantitative real-time polymerase chain reaction-based assay for marker genes involved in defense signaling pathways in lettuce. A significant higher expression of PDF 1.2 observed in the bacterized plants in response to subsequent pathogen challenge showed that FZB42 could enhance the lettuce defense response toward the fungal pathogen. To identify if surfactin or other nonribosomally synthesized secondary metabolites could elicit the observed enhanced defense gene expression, we examined two mutants of FZB42 deficient in production of surfactin and the lipopetides and polyketides, by expression analysis and pot experiments. In the absence of surfactin and other nonribosomally synthesized secondary metabolites, there was no enhanced $P D F$ 1.2-mediated response to the pathogen challenge. Pot experiment results showed that the mutants failed to reduce disease incidence in lettuce as compared with the FZB42 wild type, indicating, that surfactin as well as other nonribosomally synthesized secondary metabolites play a role in the actual disease suppression and on lettuce health. In conclusion, our study showed that nonribosomally synthesized
\end{abstract}

Corresponding Author: S. P. Chowdhury; E-mail: soumitra.pc@gmail.com

*The $\boldsymbol{e}$-Xtra logo stands for "electronic extra" and indicates that three supplementary figures and one supplementary table are published online.

(c) 2015 The American Phytopathological Society secondary metabolites of FZB42 are actually produced in the lettuce rhizosphere and contribute to the disease suppression by mediating plant defense gene expression toward the pathogen $R$. solani.

The plant-associated Bacillus amyloliquefaciens subsp. plantarum (Borriss et al. 2011) has been widely studied and is commercially available as a bioinoculant (RhizoVital42; ABiTEP $\mathrm{GmbH}$, Berlin). The type strain FZB42 has been sequenced and fully annotated (Chen et al. 2007). Several studies have shown its beneficial effects on plant growth and disease suppression (Chowdhury et al. 2013; Idris et al. 2004, 2007). The strain exhibits a high genetic capacity to nonribosomally synthesize secondary metabolites like antifungal cyclic lipopeptides, such as bacillomycin D, surfactin, fengycin, and antibacterial polyketide compounds (Chen et al. 2007, 2009; Koumoutsi et al. 2004).

The soil-borne pathogen Rhizoctonia solani AG1-IB is known to cause bottom rot on lettuce and occurrs wherever lettuce grows (Blancard et al. 2006). In general, Rhizoctonia diseases are difficult to control and effective strategies are often lacking. This has stimulated considerable research in developing environmentally friendly control methods including the use of beneficial bacteria and fungi, and several of these microbial inoculants have been reported as effective in suppression of Rhizoctonia diseases (Grosch et al. 2005, 2012). In a recent study, we could show that B. amyloliquefaciens FZB42 considerably reduced severity of bottom rot on pot- and field-grown lettuce (Chowdhury et al. 2013). The control effect shown by FZB42 could rely on the potential antifungal activity of the several bioactive secondary metabolites. However, until now, it is not demonstrated that the concentration of secondary metabolites secreted by FZB42 or other representatives of plant-associated bacilli in the plant rhizosphere is sufficient for inhibition of the pathogen by direct antibiotic action.

The response shown by a plant species to a particular pathogen is very specific and varies according to the lifestyle and the infection strategy of the pathogen concerned (Pieterse et al. 2009). The first line of plant defense responses toward phytopathogens are usually elicited from several specific compounds known as 
pathogen-associated molecular patterns (PAMPs) that are secreted or harbored by the pathogens (Jones and Dangl 2006). The exposure to the pathogen leads to a local immune response referred to as PAMP-triggered immunity, which may be followed in the distal noninfected parts as a systemic acquired resistance response (Shah and Zeier 2013; Spoel and Dong 2012). Beneficial bacteria used in biological control often show a similar mode of immune response, termed induced systemic resistance (ISR), in plants (De Vleesschauwer and Höfte 2009; Kloepper et al. 2004). ISR emerged as an important mode of action, whereby beneficial microorganisms in the rhizosphere prime the plant for enhanced defense against a range of pathogens (Pieterse et al. 2014; van Loon et al. 1998). The ISR induced by beneficial bacteria is characterized by a weak, transient, and localized defense response, but this priming leads to an enhanced expression of host defense-related genes upon subsequent attack by a pathogen (Conrath et al. 2002; Van Wees et al. 2008). Various Bacillus strains have been reported to elicit ISR in different plants, such as tomato, bell pepper, muskmelon, watermelon, sugar beet, tobacco, Arabidopsis sp., cucumber, loblolly pine, and tropical crops like cayenne pepper (Choudhary and Johri 2009; Kloepper et al. 2004). Several studies have shown that volatile organic compounds (Farag et al. 2013; Rudrappa et al. 2010; Ryu et al. 2003, 2004) and cyclic lipopeptides like surfactin and fengycin (Cawoy et al. 2014; Desoignies et al. 2013; Henry et al. 2011; Jourdan et al. 2009; Ongena et al. 2005, 2007) are important secondary metabolites produced by Bacillus spp. that are capable of eliciting immune responses in plants. There has also been speculation that, in some specific plant-pathogen systems, more than one mechanism could be acting synergistically to suppress diseases (García-Gutiérrez et al. 2013; Rudrappa et al. 2010).

This study was performed to understand the molecular and ecological interactions between FZB42 and $R$. solani in the rhizosphere of lettuce. A recently established, chemically defined axenic system with lettuce and a $g f p^{+}$(green fluorescent protein)tagged wild-type strain of FZB42 (Budiharjo et al. 2014) was used in this study. Using confocal laser scanning microscopy (CLSM), we could visualize the establishment of $R$. solani on the plants in the presence of FZB42 in the rhizosphere of lettuce. We examined the in-situ production of selected secondary metabolites by FZB42 in the lettuce rhizosphere, using ultra-high performance liquid chromatography coupled to time of flight mass spectrometry (UHPLC-qToF-MS). To examine the defense gene expression in lettuce, a quantitative real-time polymerase chain reaction (qRT-PCR)-based assay was developed for several putative genes, such as pathogenesis-related protein 1 $(P R l)$, defensin $(P D F$ 1.2), and lipoxygenase involved in salicylic acid (SA)-dependent or jasmonic acid and ethylene (JA/ET)-dependent signaling pathways. We were further interested to identify if surfactin or other nonribosomally synthesized secondary metabolites of FZB42 could be molecular determinants for the regulation of defense gene expression in lettuce plants. Therefore, we examined two mutants of FZB42, mutant CH1 deficient in production of surfactin and mutant $\mathrm{CH} 5$ deficient in the synthesis of nonribosomally synthesized lipopetides and polyketides (Chen et al. 2009). Finally, we conducted pot experiments with lettuce bacterized with FZB42 or one of the two mutants and cultivated in the presence of the pathogen $R$. solani, to assess the effect of surfactin and of lipopeptides and polyketides in the actual disease suppression and on lettuce health. Taken together, our results could show, for the first time, that lipopeptides are actually produced by FZB42 in the lettuce rhizosphere and surfactin and (possibly) other nonribosomally synthesized secondary metabolites play an important role in the actual suppression of bottom rot caused by $R$. solani. We could also demonstrate that FZB42 can mediate the plant defense response in addition to the direct antibiotic effect of secondary metabolites in the biocontrol of $R$. solani.

\section{RESULTS}

\section{FZB42 is able to delay the initial establishment} of the fungal pathogen on the plants.

To study the initial interaction between the pathogen $R$. solani and FZB42 in the rhizosphere of lettuce, we used a quartz sand based axenic system. Lettuce seedlings from surface-sterilized seed were treated with a $g f p^{+}$-tagged strain of FZB42 (FB01mut1) (Table 1) and were allowed to grow for 7 days in a growth chamber before the pathogen was inoculated, using $R$. solani-overgrown potato dextrose agar (PDA) pieces. We observed, by CLSM, a successful establishment of FZB42 in the rhizosphere of lettuce over a period of 7 days (data not shown). Plants without FZB42 treatment but with $R$. solani inoculation were used as control. Six plants per time point were sampled, with an interval of $6 \mathrm{~h}$, starting at $0 \mathrm{~h}$ postinoculation (hpi) with $R$. solani and ending at $72 \mathrm{hpi}$. CLSM observations after $R$. solani inoculation showed no growth of fungal hyphae on the root surface until $18 \mathrm{hpi}$, in both control and the FZB42-treated plants (Fig. 1). Observations after 24 hpi showed that the fungus grows toward the roots and on the hypocotyl of the control plants. In contrast, the FZB42inoculated plants did not show the presence of any fungal hyphae on both the roots and the hypocotyl (Fig. 1, $24 \mathrm{~h}$ ). However, $30 \mathrm{~h}$ after pathogen inoculation, all FZB42-inoculated plants also showed the presence of fungal hyphae on the roots to the hypocotyl region (Fig. 1, $30 \mathrm{~h}$ ).

'Damping off' symptoms, characterized by brown lesions on hypocotyls followed by seedling collapse, appeared by $48 \mathrm{hpi}$ in control plants whereas by $72 \mathrm{hpi}$ in the FZB42-inoculated plants. In the presence of $R$. solani, we could microscopically observe that the density of FZB42 gradually decreased with time (Fig. 1). The fungal pathogen could grow in a higher density on the control plant tissue within $24 \mathrm{hpi}$ and disintegration of plant cell wall was observed, possibly due to the production of cell wall-degrading enzymes by the fungal pathogen (Wibberg et al. 2013). Therefore, we selected this time point for our subsequent experiments using this model system. Thus, the study of the initial steps of bacterial, fungal, and plant interaction in the quartz sand model axenic system showed that the presence of FZB42 could delay the initial

Table 1. Bacterial strains used in this study

\begin{tabular}{|c|c|c|c|}
\hline Strain & Genotype & Description & Reference \\
\hline FZB42 & Wild type & Producer of lipopeptides and polyketides & BGSC 10A6 \\
\hline FB01mut1 & FZB42; $\Delta a m y E:: \mathrm{em}^{\mathrm{r}} g f p^{+}$ & Labeled by green fluorescent protein (GFP) & Fan et al. 2011 \\
\hline $\mathrm{CH} 1$ & FZB42; $\Delta s r f: \mathrm{Cm}^{\mathrm{R}} ; \Delta$ amyE $:: \mathrm{em}^{\mathrm{r}} g f p^{+}$ & Defective in surfactin production, with GFP marker & Chen et al. 2009 , this study \\
\hline $\mathrm{CH} 5$ & FZB $42 ; \Delta y c z E, \Delta s f p:: \mathrm{Cm}^{\mathrm{R}} ; \Delta a m y \mathrm{E}:: \mathrm{em}^{\mathrm{r}} g f p^{+}$ & $\begin{array}{l}\text { Defective in production of lipopeptides and } \\
\text { polyketides, with GFP marker }\end{array}$ & Chen et al. 2009, this study \\
\hline $\mathrm{CH} 1-\mathrm{Rif}$ & FZB 42; $\Delta s r f: \mathrm{Cm}^{\mathrm{R}} ; \Delta a m v E:: \mathrm{em}^{\mathrm{r}} g f p^{+} r i f^{+}$ & Spontaneous rifampicin resistant mutant of $\mathrm{CH} 1$ & This study \\
\hline CH5-Rif & FZB42; $\Delta y c z E ; \Delta s f p:: \mathrm{Cm}^{\mathrm{R}} ; \Delta a m y \mathrm{E}:: \mathrm{em}^{\mathrm{r}} g f p^{+} r_{i f}{ }^{+}$ & Spontaneous rifampicin resistant mutant of $\mathrm{CH} 5$ & This study \\
\hline
\end{tabular}


establishment of the fungus on the surface of plant roots and in the hypocotyl region for a few hours as compared with the nonbacterized control. This was clearly an indication that FZB42 exercises some mechanism of inhibition to delay the advancement of $R$. solani to the plants.

\section{FZB42 produces detectable amounts of secondary} metabolites in the presence of Rhizoctonia solani.

To investigate the production of three nonribosomally synthesized lipopeptides by FZB42 in comparison with its mutants, mixed culture experiments were performed. We established a UHPLC-qToF-MS method for the detection of secondary metabolites. These experiements were performed in flasks containing potato dextrose broth (PDB) medium in the presence of $R$. solani and the bacterium. The goal was to demonstrate that FZB42 and the mutants $\mathrm{CH} 1$ (srf) and CH5 $\left(y c z E^{-}, s f p^{-}\right)$(Table 1) were able to produce the lipopeptides in the presence of $R$. solani and to evaluate if our UHPLC-qToFMS method was able to detect them in the presence of fungal secondary metabolites. $R$. solani was allowed to grow in PDB for $20 \mathrm{~h}$ before the inoculation with FZB42 or its mutants. After $24 \mathrm{~h}$ of coinoculation, samples were measured as described below. Mass spectrometric analyses could detect the presence of the cyclic lipopeptides of FZB42, namely, surfactin, fengycin, and bacillomycin $\mathrm{D}$ in the culture media. Comparing mutants against FZB42, we observed a remarkable decrease of

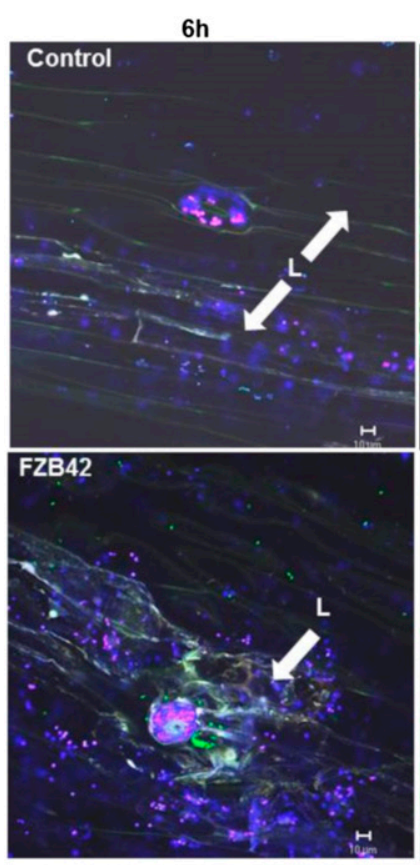

$30 \mathrm{~h}$
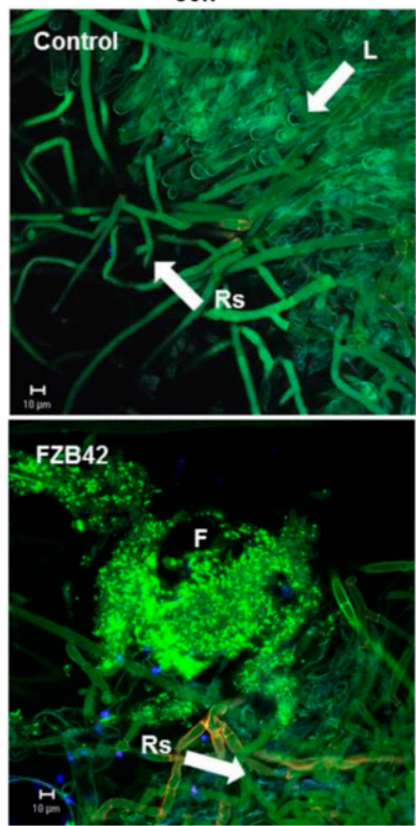

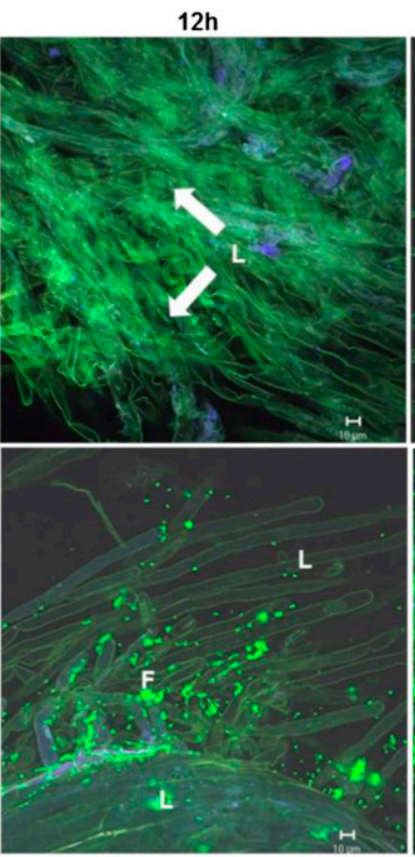

$36 \mathrm{~h}$

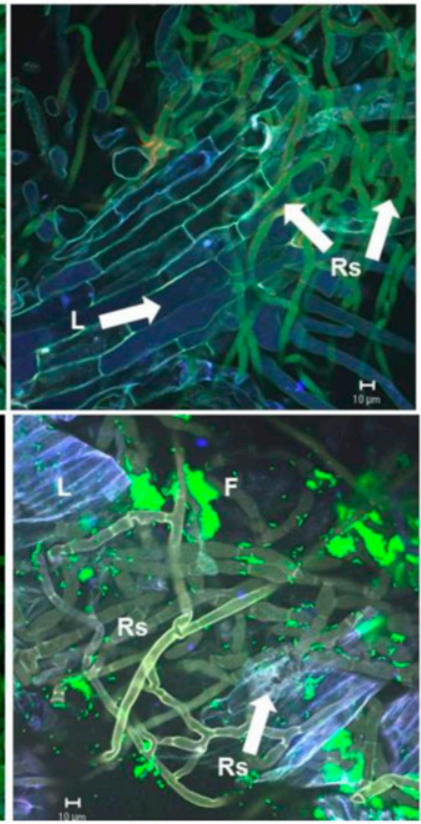

$18 \mathrm{~h}$

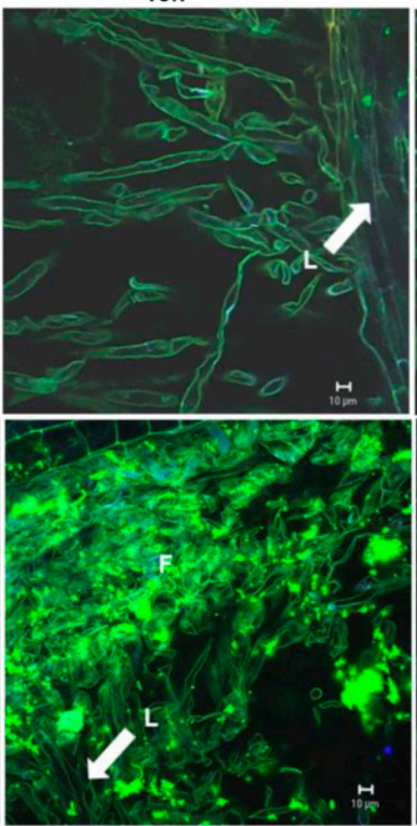

$48 \mathrm{~h}$

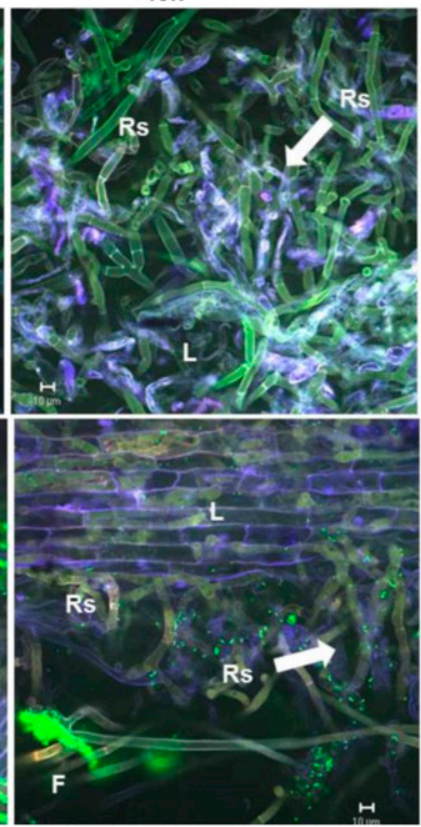

$24 h$

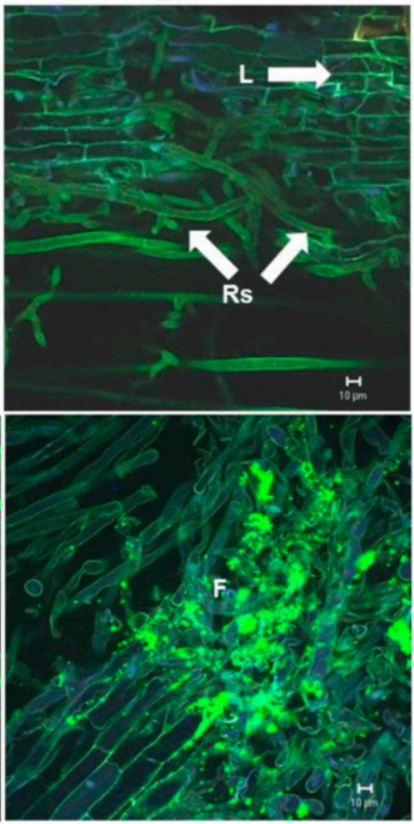

$72 \mathrm{~h}$

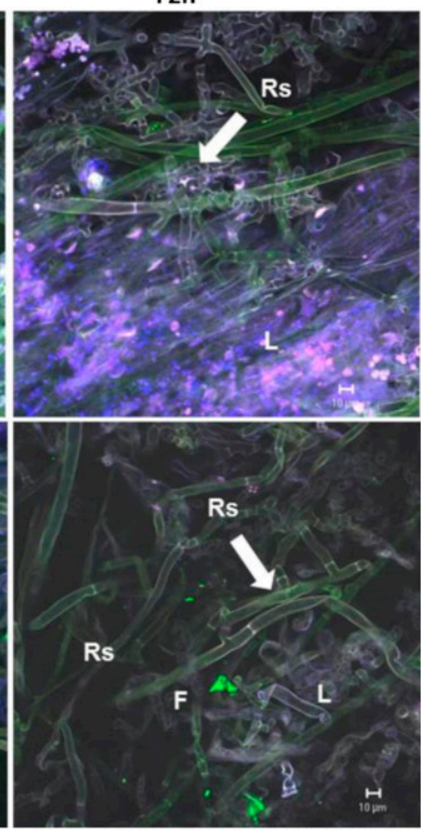

Fig. 1. Development of Rhizoctonia solani with Bacillus amyloliquefaciens FZB42 (lower panel) in the rhizosphere of lettuce. Confocal laser scanning microscopy pictures were taken at 6-h intervals up to $72 \mathrm{~h}$ postinoculation with $R$. solani. Green fluorescent protein-labeled derivatives of FZB42 (FB01mut1) were observed as fluorescing cells (F), using an excitation wavelength of $488 \mathrm{~nm}$ (argon laser). Emissions obtained using wavelengths of 543 and $633 \mathrm{~nm}$ (helium neon lasers) were used as control to visualize root structures (L) and hyphae of $R$. solani (Rs), as indicated. The disintegration of lettuce plant cell wall was observed as purple background due to autofluorescence. 
bacillomycin D in $\mathrm{CH} 1$ (defective in surfactin production) without changes in fengycin concentration. As expected, the mutant CH5 did not show the production of any of the lipopeptides examined (Fig. 2). Thus, from this experiment, we could conclude that FZB42 is able to synthesize lipopeptides that could be detected in the presence of $R$. solani.

\section{FZB42 produces secondary metabolites}

\section{in the lettuce rhizosphere.}

The actual production of lipopeptides by FZB42 in the lettuce rhizosphere has not been demonstrated to date. We performed UHPLC-qToF-MS analyses to follow the in situ production of targeted lipopeptides by FZB42 in the lettuce rhizosphere. Lettuce seedlings were bacterized with cell suspension of FZB42 and were cultivated in the axenic system for 7 days. One-week-old plants were inoculated with $R$. solani as described below. Bacterized plants without $R$. solani inoculation served as control. Three plants per treatment were sampled at time points $6,12,18$, and 24 hpi (with $R$. solani). In all analyzed FZB42 bacterized rhizosphere samples (pathogeninoculated and noninoculated ones), we could identify the three cyclic lipopeptides surfactin, fengycin, and bacillomycin D. The detected relative amounts were less in the non-pathogen inoculated compared with inoculated root extracts. The pathogeninfected samples bacterized with FZB42 showed decreased amount of surfactin within $12 \mathrm{hpi}$, followed by strong production of surfactin until 24 hpi (Fig. 3). A much lower intensity of fengycin production, although increasing, was observed over time. Monitored quantities of bacillomycin D decreased more slowly until $18 \mathrm{hpi}$ but showed an enormous increase (approximately $250 \%$ in comparison with the 18 hpi time point) within the last $6 \mathrm{~h}$. Thus, the results of mass spectrometric analyses showed the occurrence of the three investigated lipopeptides, with an increase in production of surfactin and bacillomycin D. Comparison of the relative amount of these metabolites and the parallel accomplished colonization studies furnishes

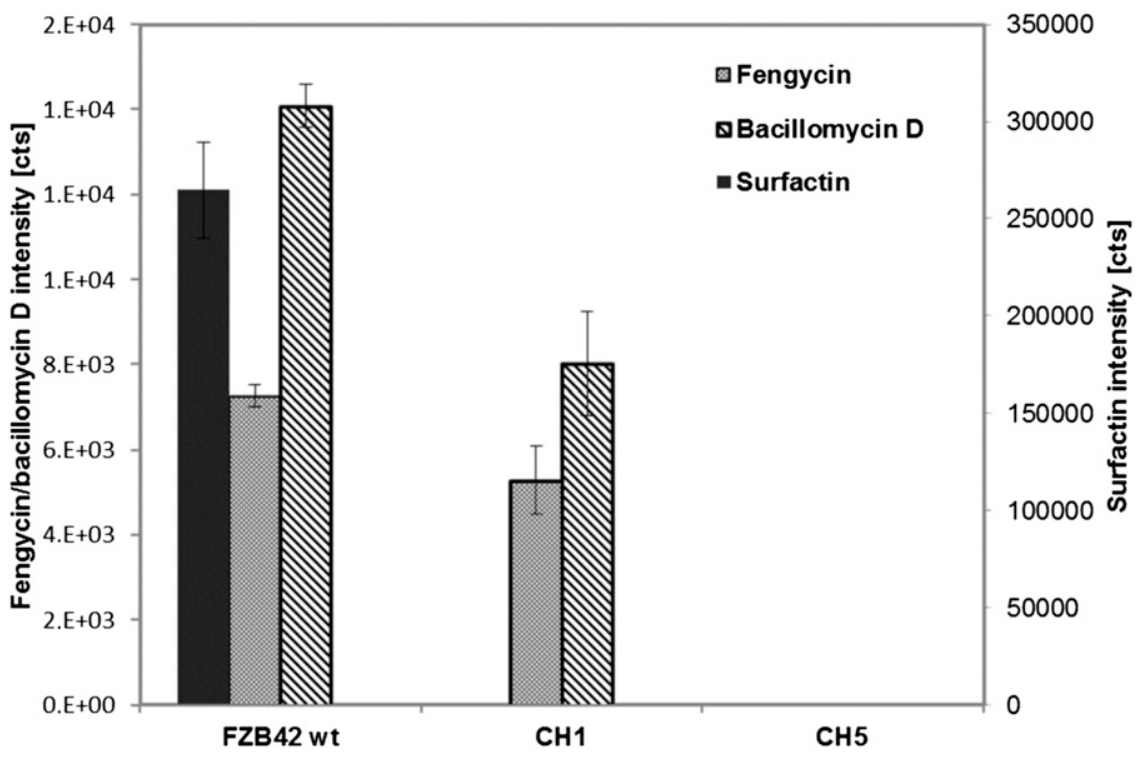

Fig. 2. Expression intensity of nonribosomally synthesized lipopeptides surfactin, fengycin, and bacillomycin D by Bacillus amyloliquefaciens FZB42 wild type (FZB42 wt) and its mutants, $\mathrm{CH} 1$ and $\mathrm{CH} 5$, in the presence of Rhizoctonia solani. Data are plotted as the average of three biological replicates \pm standard deviation.

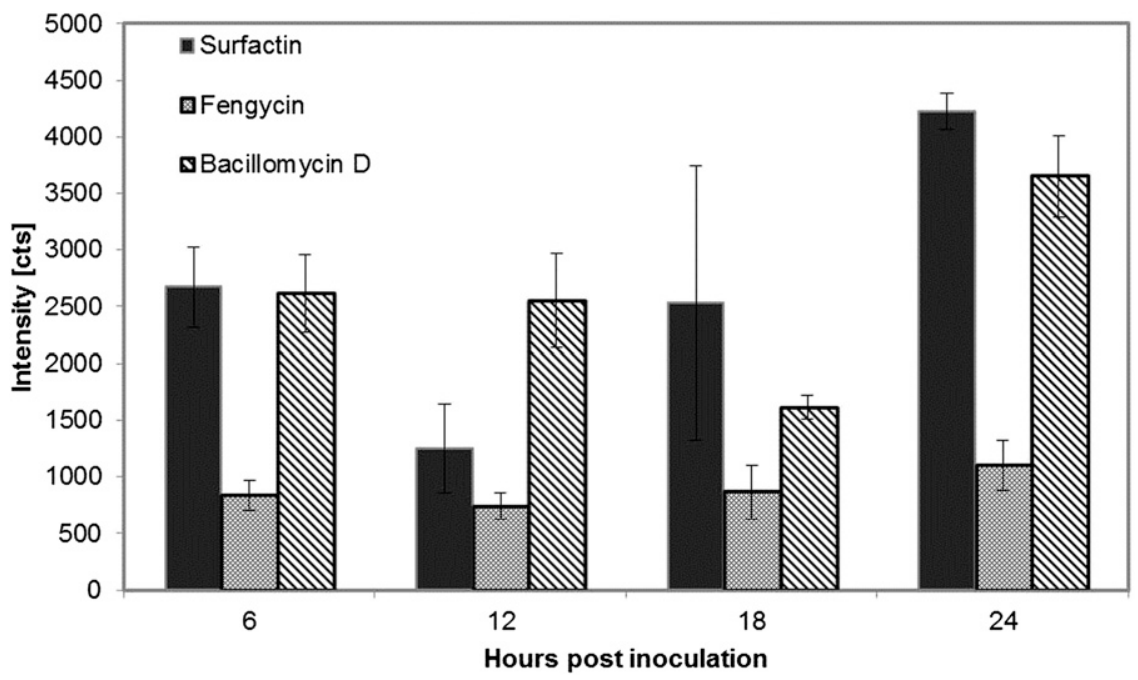

Fig. 3. Production of cyclic lipopeptides surfactin, fengycin, and bacillomycin D by FZB42 wild type in the rhizosphere of lettuce plants inoculated with Rhizoctonia solani. Data are plotted as the average of three biological replicates \pm standard deviation. Principle component analysis of combined metabolite data shows clear separation of biological replicate clusters with increasing time postinoculation with $R$. solani (Supplementary Fig. S3). 
proof of activation of the nonribosomal synthesis of secondary metabolites of FZB42 in the rhizosphere in the presence of $R$. solani. These lipopeptides may provide the necessary signal for inhibiting the pathogen by mediating the defense gene expression in the plants in addition to direct antibiosis of the pathogen.

\section{FZB42 mediates the defense response in lettuce plants.}

To determine the signaling pathways mediated by FZB42, we analyzed the expression of several plant genes known to function in SA- or JA/ET-dependent immune signaling pathways (Table 2). Axenically grown lettuce seedlings were either bacterized with FZB42 or allowed to grow as control without FZB42 for 7 days, before introducing the fungus $R$. solani in the vicinity of the plants. Plants were excised 24 hpi and RNA extraction and qRTPCR was performed. Expression of pathogenesis-related protein 1 $(P R 1)$, defensin $(P D F 1.2)$, and lipoxygenase $(L O X)$ were monitored by qRT-PCR in plants in response to FZB42 treatment alone, to $R$. solani inoculation alone, and to $R$. solani inoculation in FZB42-bacterized (for 7 days) plants.
Plants bacterized with FZB42 alone displayed a higher level of $P R 1$ and PDF 1.2 in comparison with the nonbacterized control (Fig. 4). However the expression of $L O X$ was reduced in this case. In response to $R$. solani, the nonbacterized plants showed increased expression of $P D F 1.2$ and $L O X$. The expression of $P R I$ was suppressed by the fungus. This could indicate that lettuce plants respond to $R$. solani through the JA pathway. When challenged with $R$. solani, the plants bacterized with FZB42 showed significantly high expression ( $>12$-fold) of $P D F 1.2$ as compared with the control (Fig. 4). The expression of $L O X$ was similar to that in the nonbacterized plants in response to $R$. solani. The expression of $P R l$ was not significantly higher than in plants with FZB42 in the absence of $R$. solani, indicating that the expression is not further enhanced in the presence of the pathogen. The significantly higher expression of $P D F 1.2$ observed in our experiments showed an induction of defense gene expression in the bacterized plants in response to a subsequent pathogen challenge through the expression of the JA/ET pathway. We also observed a higher expression of one selected transcription factor, ERF (data not shown), which could be involved in the JA/ET pathway.

Table 2. Genes with putative functions in salicylic acid (SA)-, jasmonic acid (JA)-, and ethylene (ET)-dependent defense signaling pathways in lettuce plants ${ }^{\mathrm{a}}$

\begin{tabular}{|c|c|c|}
\hline Gene & Putative function & Primers \\
\hline PR1 & SA inducible pathogenesis-related protein 1 & $\begin{array}{l}5^{\prime} \text {-GAGAAGGCCGATTATGATTA -3‘ } \\
5^{\circ} \text {-ATTATTGCATTGAACCCTTG -3" }\end{array}$ \\
\hline Def (PDF1.2) & JA/ET-inducible plant defensin factor (PDF1.2) & $\begin{array}{l}\text { 5'-GCCATCTTCTCTGCTTTTGAA-3' } \\
5^{\prime} \text {-ACACAAGACACTGCGACGAC-3' }\end{array}$ \\
\hline LIPO & JA inducible lipoxygenase & $\begin{array}{l}5^{\prime} \text {-AAGAGCAGAAGCCACCCATA-3' } \\
5^{\prime} \text {-GTGGAAGGAACTGCGAGAAG-3' }\end{array}$ \\
\hline$E R F$ & ET response factor controlling ET-dependent expression of PDF 1.2 & $\begin{array}{l}\text { 5'-CCGTTTGATTGTTCCGATTT-3' } \\
5^{\prime} \text {-TTCGGCTTCTTCACTGGATT-3' }\end{array}$ \\
\hline$G A D P H$ & Glyceraldehyde-3-phosphate dehydrogenase & $\begin{array}{l}\text { 5'-AGGTAGCGATCAACGGATTC-3' } \\
5^{\prime} \text {-AGGTGGGATGCTTGTTTGAC-3' }\end{array}$ \\
\hline
\end{tabular}

a Primers were designed with Primer3Plus and were selected based on quantitative polymerase chain reaction primer recommendations.

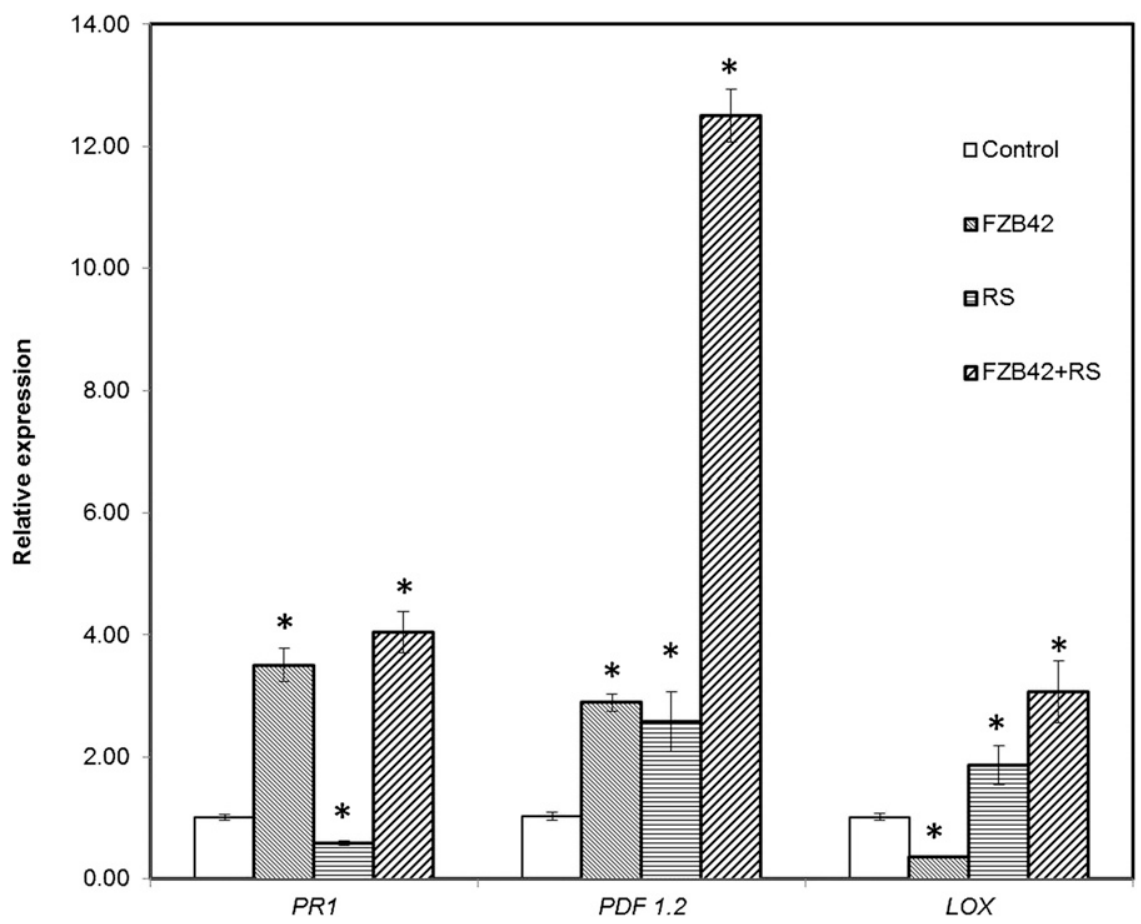

Fig. 4. Expression of pathogenesis related protein ( $P R 1)$, plant defensing factor 1.2 (PDF 1.2), and lipoxigenase $(L O X)$ genes involved in the salicylic acid- or jasmonic acid- and ethylene-dependent defense signaling pathways in lettuce. Data are expressed as the relative expression of the respective mRNAs normalized to the endogenous control GADPH. Control = noninoculated, FZB42 = bacterized with Bacillus amyloliquefaciens $\mathrm{FZB} 42$, RS $=$ control plants at $24 \mathrm{~h}$ postinoculation (hpi) with Rhizoctonia solani, and FZB42+RS = FZB42 bacterized plants at $24 \mathrm{hpi}$ with $R$. solani. Data are expressed as the average of six replicates \pm standard deviation. $P$ values were calculated using a $t$ test; asterisks $(*)$ indicate $P<0.001$ and refer to the comparison between treated samples and noninoculated control. 
Several nonribosomally synthesized secondary metabolites of FZB42 are involved in the regulation

of defense responses in lettuce plants against $R$. solani.

The qRT-PCR data from above showed that the enhanced expression of $P D F 1.2$ was an indicator for the regulation of plant defense response by FZB42. To examine the role of nonribosomally synthesized secondary metabolites in the regulation of defense responses against $R$. solani in lettuce, we bacterized axenically grown lettuce seedlings with the mutants CH5 (defective in Sfp-dependent nonribosomal synthesis of lipopeptides and polyketides) and $\mathrm{CH} 1$ (defective in surfactin production) and allowed them to grow for 7 days. The fungus $R$. solani was then inoculated in the vicinity of the plants, as described above. Plants were excised $24 \mathrm{hpi}$, and the expression of PDF 1.2 in the presence and absence of $R$. solani was examined. The mutant $\mathrm{CH} 5$ could elicit a higher expression of PDF 1.2 (compared with FZB42) in lettuce plants in the absence of the fungal pathogen. However, when challenged with $R$. solani, the plants inoculated with either one of the mutants did not exhibit a significant expression of PDF 1.2, as compared with FZB42 (Fig. 5). Our results suggest that FZB42-mediated defense gene expression in lettuce involves surfactin and (possibly) other nonribosomally synthesized secondary metabolites.

\section{Nonribosomally synthesized secondary metabolites} produced by FZB42 are involved in disease suppression.

Having demonstrated in the axenic system that FZB42 can actually produce lipopeptides in the rhizosphere of lettuce and that the mutants for surfactin $(\mathrm{CH} 1)$ and other secondary metabolites (CH5) do not show enhanced molecular defense responses, we wanted to examine if they actually play a role in the disease suppression. Two separate pot experiments were performed in a growth chamber to investigate the diseasesuppressing effect of $\mathrm{CH} 5$ and $\mathrm{CH} 1$ compared with FZB42, using rifampicin-resistant mutants (Table 1) in the lettuce-

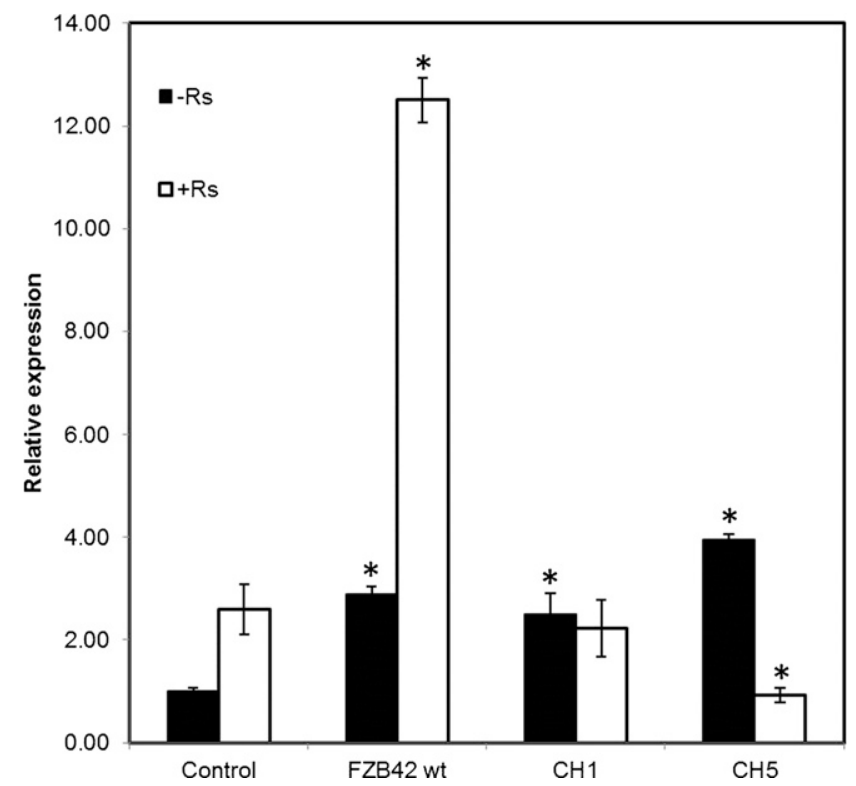

Fig. 5. Relative expression of $P D F 1.2$ in lettuce plants. Control (nonbacterized) plants are compared with plants bacterized with Bacillus amyloliquefaciens FZB42 wild type (FZB42 wt) or with mutants $\mathrm{CH} 1$ (defective in surfactin production) and $\mathrm{CH} 5$ (defective in production of lipopeptide and polyketide). $+\mathrm{RS}=$ plants at $24 \mathrm{~h}$ postinoculation with Rhizoctonia solani, $-\mathrm{RS}=$ plants without $R$. solani inoculation. Data of the respective mRNAs were normalized to the endogenous control GADPH. Data are expressed as the average of six replicates \pm standard deviation. Asterisks (*) indicate $P<0.001$ and refer to the comparison between bacterized plants and controls under the same conditions.
$R$. solani pathosystem. Each treatment included four replicates, with six plants per replicate arranged in a randomized block design. Lettuce seedlings were drenched two times with spore suspension of FZB42 or its mutants and the pathogen were inoculated after planting of lettuce into the pots. The disease suppression effect of FZB42-Rif and the mutants were assessed based on the shoot dry mass (SDM) and the number of plants with disease symptoms (disease incidence [DI]) 4 weeks after planting in both experiments.

In both pot experiments, a significantly lower SDM was observed for nonbacterized lettuce plants in the presence of $R$. solani (Table 3 ). The negative effect of the pathogen on lettuce growth could be significantly reduced by the treatment of lettuce with FZB42. This was indicated by a comparable high SDM of plants treated with FZB42 in the presence of $R$. solani (FZB42Rif + RS) and in the untreated control plants (Control) in both experiments. In contrast, a significantly lower SDM compared with the control was measured in the treatments with the mutants $\mathrm{CH} 1$ and $\mathrm{CH} 5$ in the presence of $R$. solani $(\mathrm{CH} 1-\mathrm{Rif}+\mathrm{RS}, \mathrm{CH} 5-$ Rif + RS) (Table 3). Based on the data of DI (Table 3), we could observe that the number of plants with disease symptoms, as compared with the pathogen control, was significantly reduced only when the plants were treated with FZB42. The number of diseased plants was not significantly less than the pathogen control when the plants were treated with the mutants $\mathrm{CH} 1$ and CH5. Therefore, no significant disease control effects were shown by the mutants in both experiments. FZB42 as well as mutants $\mathrm{CH} 1$ and $\mathrm{CH} 5$ were able to colonize the rhizosphere of lettuce in a sufficient density during the entire growth period in both experiments (Supplementary Table S1). No significant decrease in colonization density was observed for the FZB42 or for the mutants, considering the total CFU counted within 4 weeks. A significantly lower number of spores, compared with vegetative cells, was revealed for both mutants and the FZB42 in the first experiment two weeks after planting and for $\mathrm{CH} 5$ also 4 weeks after planting. Thus, our results show that, although both the mutants CH1-Rif and CH5-Rif were able to successfully colonize the rhizosphere of lettuce, they did not show any significant effect on the control of $R$. solani infection and reduction of disease symptoms.

\section{DISCUSSION}

Antibiosis of FZB42 and $R$. solani for root colonization.

In this study, we used a GFP-labeled derivative of FZB42 (FB01mut1) that showed a plant-specific behavior of colonizing plant roots (Dietel et al. 2013; Fan et al. 2011, 2012). Our results confirm the ability of FZB42 to establish succesfully in the rhizosphere of lettuce (Budiharjo et al. 2014). R. solani showed profuse growth and infection of, especially, the hypocotyl in

Table 3. Effect of Bacillus amyloliquefaciens FZB42-Rif and the mutants CH1-Rif and CH5-Rif on lettuce ${ }^{\mathrm{a}}$

\begin{tabular}{lrrrrc}
\hline & \multicolumn{2}{c}{ Experiment 1 } & & \multicolumn{2}{c}{ Experiment 2 } \\
\cline { 2 - 3 } Treatment & SDM & DI (\%) & & SDM & DI (\%) \\
\hline Control & $10.6 \mathrm{a}$ & 0 & & $6.5 \mathrm{a}$ & 0 \\
R. solani (+RS) & $7.9 \mathrm{~b}$ & $100 \mathrm{a}$ & & $4.7 \mathrm{~b}$ & $88 \mathrm{a}$ \\
FZB42-Rif + RS & $11.2 \mathrm{a}$ & $50 \mathrm{~b}$ & & $6.2 \mathrm{a}$ & $29 \mathrm{~b}$ \\
CH1-Rif + RS & $8.5 \mathrm{~b}$ & $65 \mathrm{a}$ & & $5.4 \mathrm{~b}$ & $57 \mathrm{a}$ \\
CH5-Rif + RS & $8.7 \mathrm{~b}$ & $85 \mathrm{a}$ & & $5.1 \mathrm{~b}$ & $64 \mathrm{a}$
\end{tabular}

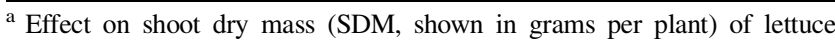
(cv. Tizian) and disease incidence (DI) percent of plants with disease symptoms) caused by Rhizoctonia solani (+RS) under controlled conditions 4 weeks after planting, in two independent experiments. Different lower case letters indicate significant differences in SDM and DI, according to Dunnett's test procedure $(P=0.05)$. 
control plants. The early steps of plant infection appear to be very similar independent of $R$. solani and host plant (Keijer 1996). The observed disintegration of the lettuce plant cell wall has also been described previously in $R$. solani-infected cauliflower (Pannecoucque and Höfte 2009). Host infection and colonization is associated with the production of cell wall-degrading enzymes, as underlined by genome analysis of the used $R$. solani isolate 7/3/14 (Wibberg et al. 2013). We could also observe that FZB42 cannot survive in the presence of the fungus, and its density decreases with time (Fig. 1 ). This could be due to one or both the production of antibacterial metabolites or competition for available root exudates by $R$. solani. Transcriptome analysis of the $R$. solani AG1-IB isolate supported its ability to produce antibiotics (Wibberg et al. 2014) that may act against FZB42 under specific axenic conditions more favorable for the pathogen, as evidenced by CLSM observations. In general, the microenvironment of the root in this axenic system is comparable to a battlefield, in that FZB42 and $R$. solani are in combat against each other, with the production of an array of metabolites to gain access to the plant.

The production of secondary metabolites by plant growthpromoting rhizobacteria provides them with an advantage over other microbes for root colonization in the highly competitive rhizosphere environment (Compant et al. 2010). An important aspect, which we also addressed in this work, is the proof that lipopeptides are actually synthesized by FZB42 in the lettuce rhizosphere. Only a few studies are available that indicate the detection of lipopeptides of bacilli in situ in the rhizosphere (Bais et al. 2004; Debois et al. 2014; Nihorimbere et al. 2012) and in the phyllosphere (Zeriouh et al. 2014). We developed a high throughput method using UHPLC-qToF-MS for fast detection of cyclic lipopeptides like surfactin, fengycin and bacillomycin $\mathrm{D}$ without time-consuming sample preparation or cost-intensive measurements. The method allows us to detect very low amounts of these secondary metabolites, such as those occurring in the rhizosphere after bacterization with FZB42. In a recent investigation, a matrix-assisted laser desorptionionization mass spectrometry imaging method was used to examine the spatiotemporal changes in the secreted antibiome of B. amyloliquefaciens S499, a close relative of FZB42, on roots of Arabidopsis thaliana, tomato, and tobacco plants (Debois et al. 2014). Surfactin was identified as the major (over $90 \%$ ) actively secreted lipopeptide compound. Very small amounts of iturins and fengycin were detected, mostly after 7 days of colonization, and no polyketides were found (Debois et al. 2014). Although this report seems to be in contrast to our results reporting detection of all three lipopeptides, on careful interpretation, it becomes clear that, in our axenic system, the first time point of measurement is 7 days after bacterization of the lettuce plants. Our earlier work shows that FZB42 can establish itself as biofilm on the lettuce roots in this period of time (Budiharjo et al. 2014). The lower amounts of fengycin detected in the rhizosphere of lettuce is in congruence with the report from Debois et al. (2014). Elaborated data showed an increasing production of surfactin and bacillomycin $\mathrm{D}$ by FZB42 within the first $24 \mathrm{~h}$, in the presence of $R$. solani. The iturin bacillomycin $\mathrm{D}$ was identified as the most powerful antifungal metabolite produced by FZB42 (Chen et al. 2009). This increase in the production of bacillomycin $\mathrm{D}$ in the presence of $R$. solani implies some kind of recognition of the fungi by FZB42, which switches on its genetic machinery to produce this antifungal compound to attack the pathogen. This is in accordance with a recent investigation with different strains of B. amyloliquefaciens, including FZB42 showing enhanced production of iturins and fengycins in response to signals emitted by phytopathogens like Fusarium oxysporum and
Botrytis cinerea (Cawoy et al. 2015) and another study demonstrating that iturins produced by $B$. amyloliquefaciens 41B1 could inhibit the germination of Verticilium dahliae microsclerotia in vitro and in the soil, with the result of a reduced disease severity of wilt on cotton under greenhouse conditions (Han et al. 2014).

\section{Role of lipopeptides in mediating lettuce defense responses.}

Based on our hypothesis that FZB42 can mediate defense response in lettuce plants in addition to the direct antagonistic effect toward $R$. solani, we studied the expression of defenserelated genes in lettuce plants. It has been observed that plants recognize the different molecular-associated molecular patterns (MAMPs) of beneficial microbes, similar to the recognition of pathogen-associated molecular patterns (PAMPs). This leads to an effective activation of the plant immune response (Van Wees et al. 2008; van der Ent et al. 2009; Pieterse et al. 2009). We could observe that FZB42 established itself in the rhizosphere of lettuce over a 7-day period and activated an expression of plant defense genes $P R 1$ and $P D F 1.2$, even in plants not infected with the pathogen. The activated priming may result in enhanced response upon pathogen challenge, as observed. A similar effect was described on Arabidopsis inoculated with endophytic actinobacteria also capable of producing bioactive secondary metabolites (Conn et al. 2008). Bacillus subtilis UMAF6639 was also shown to moderately activate LOX2 expression in melon plants before inoculation with pathogen (Zeriouh et al. 2014). It has been suggested that Bacillus spp. can actively block immune responses in Arabidopsis roots to establish a compatible interaction with their host (Niu et al. 2011). An early suppression of Arabidopsis defense genes in roots by B. subtilis FB17 to establish itself in the rhizosphere has also been reported (Lakshmanan et al. 2012). It has been speculated that JA signaling contributes partially to the suppression of root MAMP-triggered immunity. In our experimental setup, the plants were bacterized 7 days prior to the inoculation of $R$. solani, but the fungal hyphae were grown toward the roots and hypocotyl within $24 \mathrm{~h}$ (CLSM observations) and were in the vicinity of the bacterial cells. The transcriptome analysis of $R$. solani AG1-IB shows its ability to produce a number of compounds (Wibberg et al. 2014) that could be perceived by the plants triggering a PAMP-induced defense response, and we cannot specifically attribute a rhizobacteria ISR mechanism induced by FZB42, using our setup with the pathogen. However, we could clearly see that FZB42 mediates the plant defense response in distal tissues through an induction of expression of the JA/ET pathway, as indicated by rapid expression of $P D F 1.2$ in the bacterized plants in response to pathogen challenge. This is in strong accordance with a recent report showing rapid and strong upregulation of basal defense genes in cotton plants treated with iturins from Bacillus amyloliquefaciens 41B-1 against Verticillium infection (Han et al. 2014). An earlier report also shows that B. amyloliquefaciens can induce systemic resistance in oilseed rape against Botrytis cinerea through JA-dependent PDF 1.2 expression (Sarosh et al. 2009).

Several studies have shown that cyclic lipopeptides of bacilli can offer significant protection to plants against fungal pathogens by eliciting defense reactions (Jourdan et al. 2009; Ongena et al. 2007). Surfactins produced by the Bacillus sp. strain S499 have been shown to elicit systemic resistance in plants by the activation of the lipoxygenase-dependant oxylipin pathway (Ongena et al. 2007). The importance of surfactin produced by various Bacillus strains, including $B$. amyloliquefaciens FZB42, for the stimulation of plant defense has been recently examined (Cawoy et al. 2014). Using the leaf pathogen Botrytis cinerea to infect tomato plants, a considerable disease reduction 
was observed in B. amyloliquefaciens strains (S499, 98S and FZB42). This could be correlated to the relative amount of surfactin produced by the strains in a medium containing root exudates, and the levels of disease reduction were similar to those obtained by using $10 \mu \mathrm{M}$ purified surfactin (Cawoy et al. 2014). To identify if secondary metabolites of FZB42 were indeed recognized as MAMPs by lettuce plants, we examined the mutant $\mathrm{CH} 1$, which is defective in the production of surfactin (srf), and the double mutant CH5 ( $\Delta s f p, \Delta y c z E)$, deficient in the synthesis of all nonribosomally synthesized lipopeptides and polyketides of FZB42 (Chen et al. 2009). The results of failing expression of PDF1.2 in plants inoculated with the mutants (Fig. 5 ) indicates that multiple nonribosomally synthesized secondary metabolites are probably involved in the mediation of defense response shown by the wild-type FZB42. The genes sfp (phosphopantetheinyl transferase [PPTase]) and $y c z E$ (integral membrane protein with unknown function) have been described to be essential for nonribosomal synthesis of lipopeptides and for synthesis of polyketides (Chen et al. 2009). A recent study showed that a sfp mutant of B. amyloliquefaciens SQR9M6 lost its antifungal activities against different tested fungi, including $R$. solani (Li et al. 2014). Interestingly, the mutant CH5 showed ability to thrive in the presence of $R$. solani (Supplementary Fig. $\mathrm{S} 1$ ). This might indicate being incapable of producing the antifungal secondary metabolites; the fungus does not detect this mutant as a threat and, in consequence, does not produce antibacterial compounds in its presence.

\section{Biological control under complex soil conditions.}

The conditions in field-grown lettuce are completely different from those in axenic model systems for studying the production of lipopeptides in the rhizosphere (Debois et al. 2014; Nihorimbere et al. 2012). Therefore, we conducted pot experiments that simulate actual field-like growth conditions for lettuce and disease development. The importance of nonribosomally synthesized metabolites, such as surfactin in actual disease suppression, was demonstrated by results of our pot experiments with the surfactin-negative mutant $\mathrm{CH} 1$. In an earlier dual confrontation assay against $R$. solani on PDA plates, $\mathrm{CH} 1$ showed an almost equal antagonistic activity compared with FZB42, as interpreted by the zone of inhibition (Supplementary Fig. S2). This result is explained by the fact that other antifungal compounds, like bacillomycin $\mathrm{D}$, produced by this mutant $\mathrm{CH} 1$ were causing the inhibition of the fungal growth similar to FZB42. This was confirmed in another recent study with the mutant $\mathrm{CH} 1$ retaining similar inhibitory effect as compared with wild-type FZB42 on Fusarium oxysporum and Botrytis cinerea, indicating that iturin and fengycin but not surfactin are important antifungal compounds for direct antagonism of these two pathogens (Cawoy et al. 2015). However, using mutant $\mathrm{CH} 1$ in the pot studies, no efficient disease control effects were observed, although $\mathrm{CH} 1$ was able to successfully colonize the lettuce rhizosphere. This indicates that surfactin is important for disease suppression by mediating defense response of the plants and the production of other antifungal compounds alone is not sufficient to prevent the growth of the pathogen in the pots. In an earlier study, we have shown that FZB42 can positively influence the SDM of the plants in the presence of pathogen $R$. solani by reduction of the disease. In the absence of the pathogen, FZB42 did not show any growth-promoting effect on lettuce in the growth chamber (Chowdhury et al. 2013). The present study corroborates this observation. Therefore, our results indicate that, in addition to direct antibiosis due to the secondary metabolites of FZB42, an indirect mechanism of regulation of defense responses in lettuce plants through FZB42 is functional. The relevance of this induced resistance for this pathosystem is corroborated by the pathogenesis of $R$. solani, which infects the lower leaves of field-grown lettuce, while FZB42 is colonizing the roots.

Not much is known about the different signaling pathways involved in resistance mechanisms and their regulation in lettuce plants. Although we included some transcription factors for our expression study, it is rather speculative to draw conclusions from them due to lack of extensive studies with mutants targeting specific components in the SA, JA, and ET pathways. Therefore, the best estimation of the signaling pathways is based on the analogies to their counterparts in Arabidopsis and other plants. However, it should be taken into account that there might be important differences between the defense mechanisms in different plants (van Loon et al. 2006). The newly sequenced genome of lettuce (University of California Davis Genome Center) has opened up possibilities for investigating the expression of defense-related pathways in more detail. Further research in this direction would add valuable knowledge about the interactions of this commercially important plant with its beneficial microflora and pathogens.

In conclusion, our study involving mass spectrometric analyses, colonization studies, expression analysis, and pot experiments, indicates the importance of the production of lipopeptides by $B$. amyloliquefaciens FZB42 to control $R$. solani effectively. The stimulation of plant defense responses mediated by secondary metabolites of FZB42 seems to play an important role in the actual suppression of bottom rot in lettuce. The involvement of other factors, like volatiles (acetoin, and 2,3butandiol), in induction of resistance against $R$. solani needs to be addressed in a separate study. Thus, the capacity to mediate plant defense responses is expected to work in concert with the direct antibiotic effects and their colonization efficiency. making FZB42 an effective plant growthpromoting and biocontrol agent.

\section{MATERIALS AND METHODS}

\section{Bacillus strains and construction of mutants.}

In this study, we used Bacillus amyloliquefaciens FZB42 wild type and mutants described in Table 1. All strains were grown in lysogeny broth (LB) medium (Carl Roth GmbH \& Co. $\mathrm{KG}$, Karlsruhe, Germany) with respective antibiotics at $30^{\circ} \mathrm{C}$. A spontaneous rifampicin-resistant colony was selected from an overnight culture in LB medium with rifampicin as described by Koumoutsi et al. (2004), resulting in the CH1-Rif mutant. The mutant $\mathrm{CH} 5 \mathrm{gfp}$ was constructed by transformation of chromosomal DNA of CH5 into FB01mut1, according to (Chen et al. 2009). A spontaneous rifampicin-resistant mutant of CH5gfp was selected resulting in CH5gfp-Rif. The media and buffers used for DNA transformation of Bacillus cells were prepared as described by Kunst and Rapoport (1995). For pot experiments, spore suspensions prepared from FZB42 and its derivatives were used.

\section{Preparation of Rhizoctonia solani inoculum.}

The Rhizoctonia solani AG1-IB isolate 7/3/14 was obtained from the strain collection of the Leibniz Institute of Vegetable and Ornamental Crops, Großbeeren, Germany, was maintained on PDA (Merck, Darmstadt, Germany), and was used for inoculation of lettuce in the experiments. For the pot experiment, the inoculum was prepared as described by Schneider et al. (1997) on barley kernels.

\section{Axenic system for the study of FZB42}

and $R$. solani interaction in the lettuce rhizosphere.

Lactuca sativa cv. Tizian (Syngenta, Bad Salzuflen, Germany) seeds were surface-sterilized by treating with $1 \%$ Tween 
80 for $2 \mathrm{~min}$ and $13 \%$ sodium hypochloride for $10 \mathrm{~min}$, washing with sterile water (three times) in between. The sterilized seeds were placed on nutrient agar (Merck, Darmstadt, Germany) plates and were allowed to germinate in the dark for 2 days before being checked for bacterial or fungal contamination. Germinated lettuce seeds were soaked in a cell suspension of FB01mut 1 adjusted to $10^{7}$ to $10^{8} \mathrm{CFU}$ per milliliter with $0.3 \%$ $\mathrm{NaCl}$ for $1 \mathrm{~h}$ at room temperature. Bacterized seedlings were transferred to sterile plastic trays (Phytatray, Sigma-Aldrich, St. Louis) with sterilized quartz sand and $20 \mathrm{ml}$ of Hoagland's solution (Sigma). The trays were placed in a growth chamber (Vötsch BioLine VB 1514) at 20 and $18^{\circ} \mathrm{C}$ with 12 -h-light and 12-h-dark intervals. After 7 days of growth, lettuce plants at the four-leaf stage were inoculated with $R$. solani by placing PDA pieces $\left(1 \mathrm{~cm}^{2}\right)$ with fungal hyphae $2 \mathrm{~cm}$ away from each plant and $1 \mathrm{~cm}$ deep in the quartz sand. Plants without FZB42 treatment but with $R$. solani inoculation were used as control. The plants were further cultivated in the growth chamber and six plants per time point were sampled at an interval of $6 \mathrm{~h}$, starting at 0 hpi with $R$. solani and ending at 72 hpi. Plants were excised aseptically, were washed with sterile water to remove adhering quartz sand, and were cut in the hypocotyl region. Roots were mounted with antibleaching agent (Citifluor, Citifluor Ltd., London) on glass slides for microscopic observations.

\section{CLSM.}

CLSM was performed with a LSM 510 microscope (Carl Zeiss, Jena, Germany), using an excitation wavelength at $488 \mathrm{~nm}$ (argon laser) and collecting the emission band of 500 to $550 \mathrm{~nm}$ for GFP flourescence. Emissions obtained using wavelengths of 543 and $633 \mathrm{~nm}$ (helium neon lasers) were used as control to visualize root structure. Images were aquired and reconstructed using the Zeiss LSM Image browser.

\section{Mixed-culture experiments}

to analyze secondary metabolites.

For in vitro mixed-culture experiments, flasks (three per treatment) containing $50 \mathrm{ml}$ of $50 \%$ PDB medium were inoculated with one sclerotia of $R$. solani (produced on PDA plates) and were cultivated at $28^{\circ} \mathrm{C}$ and $90 \mathrm{rpm}$. After $20 \mathrm{~h}$ of fungal growth, the flasks were inoculated with $1 \mathrm{ml}$ of each corresponding bacterial wild-type or mutant cell suspension (around $10^{7}$ to $10^{8} \mathrm{CFU} / \mathrm{ml}$ ) and were further incubated for $24 \mathrm{~h}$. Samples $(10 \mathrm{ml})$ were taken from each flask $24 \mathrm{~h}$ after coinoculation with FZB42. Samples were centrifuged for $10 \mathrm{~min}$ at $5,000 \mathrm{rpm}$ and $4^{\circ} \mathrm{C}$, and pellets were separated from supernatants. In liquid nitrogen, quenched pellets were then extracted for 20 min with $80 \%$ methanol (CHROMASOLV LCMS; Fluka, Sigma-Aldrich Laborchemikalien GmbH, Germany) in an ultrasonic bath, were evaporated using a SpeedVac system (Thermo Scientific, Waltham, MA, U.S.A.), and were solved in water for UHPLC-qToF-MS analyses.

\section{Analyzing secondary metabolites in Lactuca sativa rhizosphere.}

Germinated lettuce seeds were bacterized with FZB42 and were cultivated in the axenic system as described above for 7 days. Root colonization was confirmed by parallel experiments using CLSM. One-week-old plants were coinoculated with $R$. solani as described above. Plants bacterized with FZB42 but not inoculated with $R$. solani were used as control. Three plants per treatment were sampled at time points 6,12 , 18 , and 24 hpi. Plants were cut at the hypocotyl region and the root system was cleaned carefully from adhering quartz sand. Complete roots were transferred in $2 \mathrm{ml}$ of ice-cold solvent mixture of $80 \%$ methanol (CHROMASOLV LC-MS, Fluka) in water and was extracted about $20 \mathrm{~min}$ in tempered $\left(0^{\circ} \mathrm{C}\right) \mathrm{ul}-$ trasonic bath. One-milliliter aliquots of supernatants were evaporated and resumed in water.

\section{UHPLC-qToF-MS analyses of secondary metabolites.}

Measurements were performed by an Acquity UPLC system (Waters Corporation, Milford, MA, U.S.A.) coupled to a time-offlight mass spectrometer equipped with an Apollo II electrospray ionization source (maXis, Bruker Daltonik, Bremen, Germany). The reversed-phase seperation is adapted from Hu et al. (2008). Chromatographic separation was achieved on an Acquity BEH C18 column packed with $1.7-\mu \mathrm{m}$ particles and dimensions of $1.0 \times 50 \mathrm{~mm}$ (Waters Corporation). The temperatures of samples and column were set to $4^{\circ} \mathrm{C}$ and $40^{\circ} \mathrm{C}$ respectively. Each sample $(5 \mu \mathrm{l})$ was injected through a partial loop. The mobile phases consisted of A $(60 \%$ acetonitrile in water containing $10 \mathrm{mM}$ ammonium formate) and B (90\% i-propanol, $10 \%$ acetonitrile containing $10 \mathrm{mM}$ ammonium formate and $0.1 \%$ formic acid) and were set to a flow rate of $0.2 \mathrm{ml} / \mathrm{min}$. All chemicals were at least of HPLC grade and were supplied by Sigma. An elution gradient was adjusted for $4 \mathrm{~min}$, holding the initial composition of $99 \% \mathrm{~A}$ and $1 \% \mathrm{~B}$ for $0.5 \mathrm{~min}$, followed by a linear ramp up to $99 \%$ B within $1 \mathrm{~min}$. By holding 99\% B for $1.5 \mathrm{~min}$, sufficient seperation of lipopeptides was achieved. Another linear gradient at 3 min set initial conditions and the pre-runtime of 2 min was used for column re-equilibration. The detection wavelength was set to $230 \mathrm{~nm}$ with a scan rate of $20 \mathrm{~Hz}$, and mass spectra were acquired in positive ionization mode within a mass range of 100 to $2,000 \mathrm{~m} / \mathrm{z}$. Chromatograms and spectra were processed with DataAnalysis 4.0 (Bruker Daltonik).

\section{Study of plant defense responses.}

Lettuce seedlings were bacterized with cell suspension of FZB42 or mutants $\mathrm{CH} 1$ and $\mathrm{CH} 5$ and were cultivated in the axenic system, as described above. Control plants were drenched with $1 \mathrm{ml}$ of sterile $0.3 \% \mathrm{NaCl}$ instead of bacterial cell suspension. The trays were placed in a growth chamber (Vötsch BioLine VB 1514) at 20 and $18^{\circ} \mathrm{C}$ with 12 -h-light and 12-h-dark intervals for 7 days to ensure the root colonization of FZB42. One-week-old plants were inoculated with $R$. solani as described above. Plants were incubated in the growth chamber for $24 \mathrm{~h}$ before RNA extraction.

\section{Selection of target genes and primer design.}

Target genes of lettuce showing similarity to a known or deduced function involved in the SA and JA/ET pathways were selected based on previously published expressed sequence tags (Klosterman et al. 2011) from the National Center for Biotechnology Information (NCBI) dEST database. Namely PRI (an SA-responsive marker gene), defensin (PDF 1.2) (JA/ET response marker gene), lipoxygenase ( $L O X$ ) (a JA-responsive marker gene) and an ethylene response factor $(E R F)$ that could be expressed in the plant defense mechanism (Pieterse et al. 2009; van Loon et al. 2006) were used in this study. The complete sequences of the corresponding genes selected were obtained from the Lactuca sativa whole genome shotgun sequencing project at NCBI (BioProject database, PRJNA68025). BlastX (Altschul et al. 1997) searches were performed against the NCBI nr database to identify conserved regions in the selected genes. The candidate reference genes corresponding to ubiquitin (Ubi), protein phosphatase $2 \mathrm{~A}$ $(P P 2 A)$, glyceraldehyde-3-dehydrogenase $(G A D P H)$, and actin $(A C T)$ were selected for normalization of gene expression in lettuce. The expression stability of these genes was analyzed using NormFinder software (Andersen et al. 2004). GADPH was identified as the most stable gene and was used as an endogenous control in qRT-PCR analysis. 
The primer pairs used for the qRT-PCR analysis (Table 2) were designed according to the parameters established on the Primer3Plus program (Untergasser et al. 2007). The primer gene specificity was checked by PCR on cDNA and the amplicons were sequenced. The amplicon sequences were aligned against the Lactuca sativa whole-genome shotgun sequencing project, using BLAST at NCBI.

\section{qRT-PCR.}

qPCR was performed as described previously (Alquéres et al. 2013) with some modifications. Five plants were pooled, and total RNA was extracted from the aerial parts with TRizol (Life Technologies, Carlsbad, CA, U.S.A.), from frozen material, according to manufacturer's instructions and was followed by DNaseI (Promega Corp., Madison, WI, U.S.A.) treatment. RNA (1 $\mu \mathrm{g})$ was used for cDNA synthesis, using the highcapacity cDNA reverse transcription kit with RNase inhibitor (Applied Biosystems, Foster City, CA, U.S.A.). Expression of selected genes were determined by RT-qPCR with Power SYBR green supermix (Applied Biosystems) using an iCycler thermal cycler (Applied Biosystems). cDNA dilutions $(1 \mu \mathrm{l}$, 1:4) were used as PCR templates. Each PCR reaction contained $12.5 \mu \mathrm{l}$ of $2 \times$ Power SYBR green supermix, $0.4 \mu \mathrm{M}$ primers (Eurofins MVG Operon, Ebersberg, Germany), and $1 \mu \mathrm{l}$ of template in a $25-\mu \mathrm{l}$ reaction. $\mathrm{PCR}$ reactions were heated to $95^{\circ} \mathrm{C}$ for $3 \mathrm{~min}$ and, then, for 40 cycles with steps of $95^{\circ} \mathrm{C}$ for $30 \mathrm{~s}$, $60^{\circ} \mathrm{C}$ for $30 \mathrm{~s}$, and $60^{\circ} \mathrm{C}$ for $30 \mathrm{~s}$. The generation of specific PCR products was confirmed by melting-curve analysis and gel electrophoresis. The $2^{-\Delta \Delta \mathrm{Ct}}$ method (Livak and Schmittgen 2001) was employed for relative quantification. The quantity of interested genes was normalized to the quantity of the endogenous control gene for each condition. The experiments were done in biological triplicates (each with two technical replicates). Results were based on the average of triplicates and the standard deviation of the mean is shown.

\section{Pot experiments for study \\ of disease suppression effects of FZB42 mutants.}

In two independent experiments, lettuce seeds (cv. Tizian) were cultivated as described by Chowdhury et al. (2013). Lettuce plants were planted at the two-leaf stage into pots $(500 \mathrm{ml})$ filled with a mixture of quartz sand and Fruhsdorfer Einheitserde Typ P (Vechta, Germany; chemical analysis [mg/liter]: $\mathrm{N}=120, \mathrm{P}=120, \mathrm{~K}=170, \mathrm{Mg}=120, \mathrm{~S}=100, \mathrm{KCl}=1$, organic substance $=167$, peat $=309 ; \mathrm{pH} 5.9)$ at a $1: 1 \mathrm{ratio}(\mathrm{vol} / \mathrm{vol})$ and cultivated at 22 and $15^{\circ} \mathrm{C}$ until harvest in a growth chamber (York, Mannheim, Germany) (16-h-day and 8-h-night cycle, $500 \mu \mathrm{mol} \mathrm{m} \mathrm{m}^{-2} \mathrm{~s}^{-1}, 60$ and $80 \%$ relative humidity). For inoculation of lettuce with $R$. solani, two infested barley kernels were placed $1 \mathrm{~cm}$ deep and $2 \mathrm{~cm}$ apart from the seedlings 1 day after planting. The pots were watered lightly each day to maintain the substrate moisture and were fertilized weekly (0.2\% Wuxal TOP N; Wilhelm Haug GmbH \& Co. KG, Düsseldorf, Germany). Each treatment included four replicates with six plants per replicate arranged in a randomized block design. The disease suppression effect of FZB42-Rif and the mutants $\mathrm{CH} 1$-Rif and $\mathrm{CH} 5$-Rif were assessed based on the SDM and the number of plants with disease symptoms (DI) 4 weeks after planting in both experiments.

For bacterization of lettuce with FZB42-Rif and the mutants CH1-Rif and CH5-Rif, each plant was drenched with $10 \mathrm{ml}$ of the corresponding spore suspension $\left(10^{7}\right.$ spores $\left./ \mathrm{ml}\right)$ at the twoleaf stage 1 week before pathogen inoculation and with a $20-\mathrm{ml}$ spore suspension $\left(10^{7}\right.$ spores $\left./ \mathrm{ml}\right)$ at the three-leaf stage at planting.

The survival and root colonization efficiency of FZB42-Rif and the mutants CH1-Rif and CH5-Rif was evaluated 2 and
4 weeks after planting into the pots as described by Chowdhury et al. (2013).

\section{Statistical analysis.}

The data analysis was performed with the STATISTICA program (StatSoft Inc., Tulsa, Ok U.S.A.). The SDM, DI, and inoculant densities (CFU) were analyzed using analysis of variance with Dunnett's test procedure, with $P<0.05$.

\section{ACKNOWLEDGMENTS}

The work was supported by funds from the German Ministry for Education and Research (PATHCONTROL 0315654C) to A. Hartman, R. Borriss, and K. Dietel were supported by grants from PATHCONTROL (Bundesministerium für Bildung und Forschung) and BIOFECTOR, funded by the European Union within the 7th Framework Program Grant agreement number 312117 .

\section{LITERATURE CITED}

Alquéres, S., Meneses, C., Rouws, L., Rothballer, M., Baldani, I., Schmid, M., and Hartmann, A. 2013. The bacterial superoxide dismutase and glutathione reductase are crucial for endophytic colonization of rice roots by Gluconacetobacter diazotrophicus PAL5. Mol. Plant Microbe Interact. 26:937-945.

Altschul, S. F., Madden, T. L., Schäffer, A. A., Zhang, J., Zhang, Z., Miller, W., and Lipman, D. J. 1997. Gapped BLAST and PSI-BLAST: A new generation of protein database search programs. Nucleic Acids Res. 25:3389-3402.

Andersen, C. L., Ledet-Jensen, J., and Ørntoft, T. 2004. Normalization of real-time quantitative reverse transcription-PCR data: A model-based variance estimation approach to identify genes suited for normalization applied to bladder- and colon-cancer data-sets. Cancer Res. 64: 5245-5250

Bais, H. P., Fall, R., and Vivanco, J. M. 2004. Biocontrol of Bacillus subtilis against infection of Arabidopsis roots by Pseudomonas syringae is facilitated by biofilm formation and surfactin production. Plant Physiol. 134:307-319.

Blancard, D., and Lot, H., and Maisonneuve, B. 2006. A Color Atlas of Disease of Lettuce and Related Salad Crops: Observation, Biology and Control. Academic Press, New York.

Borriss, R., Chen, X. H., Rueckert, C., Blom, J., Becker, A., Baumgarth, B., Fan, B., Pukall, R., Schumann, P., Spröer, C., Junge, H., Vater, J., Pühler, A., and Klenk, H. P. 2011. Relationship of Bacillus amyloliquefaciens clades associated with strains DSM 7T and FZB42T: A proposal for Bacillus amyloliquefaciens subsp. amyloliquefaciens subsp. nov. and Bacillus amyloliquefaciens subsp. plantarum subsp. nov. based on complete genome sequence comparisons. Int. J. Syst. Evol. Microbiol. 61:1786-1801.

Budiharjo, A., Chowdhury, S. P., Dietel, K., Beator, B., Dolgova, O., Fan, B., Bleiss, W., Ziegler, J., Schmid, M., Hartmann, A., and Borriss, R. 2014. Transposon mutagenesis of the plant-associated Bacillus amyloliquefaciens ssp. plantarum FZB42 revealed that the nfrA and RBAM17410 genes are involved in plant-microbe-interactions. PLoS ONE 9:e98267.

Cawoy, H., Debois, D., Franzil, L., De Pauw, E., Thonart, P., and Ongena, M. 2015. Lipopeptides as main ingredients for inhibition of fungal phytopathogens by Bacillus subtilis/amyloliquefaciens. Microb. Biotechnol. 8:281-295.

Cawoy, H., Mariutto, M., Henry, G., Fisher, C., Vasilyeva, N., Thonart, P., Dommes, J., and Ongena, M. 2014. Plant defense stimulation by natura isolates of Bacillus depends on efficient surfactin production. Mol. Plant Microbe Interact. 27:87-100.

Chen, X. H., Koumoutsi, A., Scholz, R., Eisenreich, A., Schneider, K. Heinemeyer, I., Morgenstern, B., Voss, B., Hess, W. R., Reva, O., Junge, H., Voigt, B., Jungblut, P. R., Vater, J., Süssmuth, R., Liesegang, H., Strittmatter, A., Gottschalk, G., and Borriss, R. 2007. Comparative analysis of the complete genome sequence of the plant growthpromoting bacterium Bacillus amyloliquefaciens FZB42. Nat. Biotechnol. 25:1007-1014.

Chen, X. H., Scholz, R., Borriss, M., Junge, H., Mögel, G., Kunz, S., and Borriss, R. 2009. Difficidin and bacilysin produced by plant-associated Bacillus amyloliquefaciens are efficient in controlling fire blight disease. J. Biotechnol. 140:38-44.

Choudhary, D. K., and Johri, B. N. 2009. Interactions of Bacillus spp. and plants-With special reference to induced systemic resistance (ISR). Microbiol. Res. 164:493-513. 
Chowdhury, S. P., Dietel, K., Rändler, M., Schmid, M., Junge, H., Borriss, R., Hartmann, A., and Grosch, R. 2013. Effects of Bacillus amylolique faciens FZB42 on lettuce growth and health under pathogen pressure and its impact on the rhizosphere bacterial community. PLoS ONE 8:e68818.

Compant, S., Clement, C., and Sessitsch, A. 2010. Plant growth-promoting bacteria in the rhizo- and endosphere of plants: Their role, colonization mechanisms involved and prospects for utilization. Soil Biol. Biochem. 42:669-678.

Conn, V. M., Walker, A. R., and Franco, C. M. 2008. Endophytic actinobacteria induce defense pathways in Arabidopsis thaliana. Mol. Plant Microbe Interact. 21:208-218.

Conrath, U., Pieterse, C. M., and Mauch-Mani, B. 2002. Priming in plantpathogen interactions. Trends Plant Sci. 7:210-216.

De Vleesschauwer, D., and Höfte, M. 2009. Rhizobacteria-Induced Systemic Resistance. Pages 223-281 in: Plant Innate Immunity, Vol. 51. L. C. Van Loon, ed. Academic Press/Elsevier, London

Debois, D., Jourdan, E., Smargiasso, N., Thonart, P., De Pauw, E., and Ongena, M. 2014. Spatiotemporal monitoring of the antibiome secreted by Bacillus biofilms on plant roots using MALDI mass spectrometry imaging. Anal. Chem. 86:4431-4438.

Desoignies, N., Schramme, F., Ongena, M., and Legrève, A. 2013. Systemic resistance induced by Bacillus lipopeptides in Beta vulgaris reduces infection by the rhizomania disease vector Polymyxa betae. Mol. Plant Pathol. 14:416-421.

Dietel, K., Beator, B., Budiharjo, A., Fan, B., and Borriss, R. 2013. Bacterial traits involved in colonization of Arabidopsis thaliana roots by Bacillus amyloliquefaciens FZB42. Plant Pathol. J. 29:59-66.

Fan, B., Borriss, R., Bleiss, W., and Wu, X. 2012. Gram-positive rhizobacterium Bacillus amyloliquefaciens FZB42 colonizes three types of plants in different patterns. J. Microbiol. 50:38-44.

Fan, B., Chen, X. H., Budiharjo, A., Bleiss, W., Vater, J., and Borriss, R. 2011. Efficient colonization of plant roots by the plant growth promoting bacterium Bacillus amyloliquefaciens FZB42, engineered to express green fluorescent protein. J. Biotechnol. 151:303-311.

Farag, M. A., Zhang, H., and Ryu, C. M. 2013. Dynamic chemical communication between plants and bacteria through airborne signals: Induced resistance by bacterial volatiles. J. Chem. Ecol. 39:1007-1018.

García-Gutiérrez, L., Zeriouh, H., Romero, D., Cubero, J., de Vicente, A. and Pérez-García, A. 2013. The antagonistic strain Bacillus subtilis UMAF6639 also confers protection to melon plants against cucurbit powdery mildew by activation of jasmonate- and salicylic aciddependent defence responses. Microb. Biotechnol. 6:264-274.

Grosch, R., Dealtry, S., Schreiter, S., Berg, G., Mendoca-Hagler, L., and Smalla, K. 2012. Biocontrol of Rhizoctonia solani: Complex interaction of biocontrol strains, pathogen and indigenous microbial community in the rhizosphere of lettuce shown by molecular methods. Plant Soil 361:343-357.

Grosch, R., Faltin, F., Lottmann, J., Kofoet, A., and Berg, G. 2005. Effectiveness of 3 antagonistic bacterial isolates to control Rhizoctonia solani Kühn on lettuce and potato. Can. J. Microbiol. 51:345-353.

Han, Q., Wu, F., Wang, X., Qi, H., Shi, L., Ren, A., Liu, Q., Zhao, M., and Tang, C. 2014. The bacterial lipopeptide iturins induce Verticillium dahliae cell death by affecting fungal signaling pathways and mediate plant defence responses involved in PAMP-triggered immunity. Environ. Microbiol. 17:1166-1188.

Henry, G., Deleu, M., Jourdan, E., Thonart, P., and Ongena, M. 2011. The bacterial lipopeptide surfactin targets the lipid fraction of the plant plasma membrane to trigger immune-related defence responses. Cell. Microbiol. 13:1824-1837.

Hu, C., van Dommelen, J., van der Heijden, R., Spijksma, G., Reijmers, T. H., Wang, M., Slee, E., Lu, X., Xu, G., van der Greef, J., and Hankemeier, T. 2008. RPLC-ion-trap-FTMS method for lipid profiling of plasma: Method validation and application to p53 mutant mouse model. J. Proteome Res. 7:4982-4991.

Idris, E. E., Bochow, H., Ross, H., and Borriss, R. 2004. Use of Bacillus subtilis as biocontrol agent. VI. Phytohormone-like action of culture filtrates prepared from plant growth-promoting Bacillus amyloliquefaciens FZB24, FZB42, FZB45 and Bacillus subtilis FZB37. J. Plant Dis. Prot. 111:583-597.

Idris, E. E., Iglesias, D. J., Talon, M., and Borriss, R. 2007. Tryptophandependent production of indole-3-acetic acid (IAA) affects level of plant growth promotion by Bacillus amyloliquefaciens FZB42. Mol. Plant Microbe Interact. 20:619-626.

Jones, J. D., and Dangl, J. L. 2006. The plant immune system. Nature 444: 323-329.

Jourdan, E., Henry, G., Duby, F., Dommes, J., Barthélemy, J. P., Thonart, P., and Ongena, M. 2009. Insights into the defense-related events occurring in plant cells following perception of surfactin-type lipopeptide from Bacillus subtilis. Mol. Plant Microbe Interact. 22:456-468.
Keijer, J. 1996. The initial steps of the infection process in Rhizoctonia solani. Pages 149-162 in: Rhizoctonia species: Taxonomy, Molecular Biology, Ecology, Pathology and Disease Control. B. Sneh, S. JabajiHare, S. M. Neate, and G. Dijst. eds. Kluwer Academic, Dordrecht, The Netherlands.

Kloepper, J. W., Ryu, C. M., and Zhang, S. 2004. Induced systemic resistance and promotion of plant growth by Bacillus spp. Phytopathology 94:1259-1266.

Klosterman, S., J., Anchieta, A., Garcia-Pedrajas, M., D., Maruthachalam, K., Hayes, R., J., and Subbarao, K., V. 2011. SSH reveals a linkage between a senescence-associated protease and Verticillium wilt symptom development in lettuce (Lactuca sativa). Physiol. Mol. Plant Pathol. 76:48-58.

Koumoutsi, A., Chen, X. H., Henne, A., Liesegang, H., Hitzeroth, G., Franke, P., Vater, J., and Borriss, R. 2004. Structural and functional characterization of gene clusters directing nonribosomal synthesis of bioactive cyclic lipopeptides in Bacillus amyloliquefaciens strain FZB42. J. Bacteriol. 186:1084-1096.

Kunst, F., and Rapoport, G. 1995. Salt stress is an environmental signal affecting degradative enzyme synthesis in Bacillus subtilis. J. Bacteriol. 177:2403-2407.

Lakshmanan, V., Kitto, S. L., Caplan, J. L., Hsueh, Y. H., Kearns, D. B., Wu, Y. S., and Bais, H. P. 2012. Microbe-associated molecular patternstriggered root responses mediate beneficial rhizobacterial recruitment in Arabidopsis. Plant Physiol. 160:1642-1661.

Li, B., Li, Q., Xu, Z., Zhang, N., Shen, Q., and Zhang, R. 2014. Responses of beneficial Bacillus amyloliquefaciens SQR9 to different soilborne fungal pathogens through the alteration of antifungal compounds production. Front Microbiol 5:636

Livak, K. J., and Schmittgen, T. D. 2001. Analysis of relative gene expression data using real-time quantitative PCR and the $2^{-\Delta \Delta \mathrm{Ct}}$ Method. Methods 25:402-408.

Nihorimbere, V., Cawoy, H., Seyer, A., Brunelle, A., Thonart, P., and Ongena, M. 2012. Impact of rhizosphere factors on cyclic lipopeptide signature from the plant beneficial strain Bacillus amyloliquefaciens S499. FEMS (Fed. Eur. Microbiol. Soc.) Microbiol. Ecol. 79:176-191.

Niu, D. D., Liu, H. X., Jiang, C. H., Wang, Y. P., Wang, Q. Y., Jin, H. L., and Guo, J. H. 2011. The plant growth-promoting rhizobacterium Bacillus cereus AR156 induces systemic resistance in Arabidopsis thaliana by simultaneously activating salicylate- and jasmonate/ethylene-dependent signaling pathways. Mol. Plant Microbe Interact. 24:533-542.

Ongena, M., Jacques, P., Touré, Y., Destain, J., Jabrane, A., and Thonart, P. 2005. Involvement of fengycin-type lipopeptides in the multifaceted biocontrol potential of Bacillus subtilis. Appl. Microbiol. Biotechnol. 69:29-38.

Ongena, M., Jourdan, E., Adam, A., Paquot, M., Brans, A., Joris, B., Arpigny, J. L., and Thonart, P. 2007. Surfactin and fengycin lipopeptides of Bacillus subtilis as elicitors of induced systemic resistance in plants. Environ. Microbiol. 9:1084-1090.

Pannecoucque, J., and Höfte, M. 2009. Interactions between cauliflower and Rhizoctonia anastomosis groups with different levels of aggressiveness. BMC Plant Biol. 9:95.

Pieterse, C. M., Leon-Reyes, A., Van der Ent, S., and Van Wees, S. C. 2009 Networking by small-molecule hormones in plant immunity. Nat. Chem. Biol. 5:308-316.

Pieterse, C. M., Zamioudis, C., Berendsen, R. L., Weller, D. M., Van Wees, S. C., and Bakker, P. A. 2014. Induced systemic resistance by beneficial microbes. Annu. Rev. Phytopathol. 52:347-375.

Rudrappa, T., Biedrzycki, M. L., Kunjeti, S. G., Donofrio, N. M., Czymmek, K. J., Paré, P. W., and Bais, H. P. 2010. The rhizobacterial elicitor acetoin induces systemic resistance in Arabidopsis thaliana. Commun. Integr. Biol. 3:130-138.

Ryu, C. M., Farag, M. A., Hu, C. H., Reddy, M. S., Kloepper, J. W., and Paré, P. W. 2004. Bacterial volatiles induce systemic resistance in Arabidopsis. Plant Physiol. 134:1017-1026.

Ryu, C. M., Farag, M. A., Hu, C. H., Reddy, M. S., Wei, H. X., Paré, P. W., and Kloepper, J. W. 2003. Bacterial volatiles promote growth in Arabidopsis. Proc. Natl. Acad. Sci. U.S.A. 100:4927-4932.

Sarosh, B. R., Danielsson, J., and Meijer, J. 2009. Transcript profiling of oilseed rape (Brassica napus) primed for biocontrol differentiate genes involved in microbial interactions with beneficial Bacillus amyloliquefaciens from pathogenic Botrytis cinerea. Plant Mol. Biol. 70:31-45.

Schneider, J., H., M., Schilder, M., T., and Dijst, G. 1997. Characterization of Rhizoctonia solani AG 2 isolates causing bare patch in field grown tulips in the Netherlands. Eur. J. Plant Pathol. 103:265-279.

Shah, J., and Zeier, J. 2013. Long-distance communication and signal amplification in systemic acquired resistance. Front. Plant Sci. 4:30.

Spoel, S. H., and Dong, X. 2012. How do plants achieve immunity? Defence without specialized immune cells. Nat. Rev. Immunol. 12:89-100. 
Untergasser, A., Nijveen, H., Rao, X., Bisseling, T., Geurts, R., and Leunissen, J. A. 2007. Primer3Plus, an enhanced web interface to Primer3. Nucleic Acids Res. 35:W71-W74.

Van der Ent, S., Van Wees, S. C., and Pieterse, C. M. 2009. Jasmonate signaling in plant interactions with resistance-inducing beneficial microbes. Phytochemistry 70:1581-1588.

van Loon, L. C., Bakker, P. A., and Pieterse, C. M. 1998. Systemic resistance induced by rhizosphere bacteria. Annu. Rev. Phytopathol. 36:453-483.

van Loon, L. C., Rep, M., and Pieterse, C. M. 2006. Significance of inducible defense-related proteins in infected plants. Annu. Rev. Phytopathol. 44: 135-162.

Van Wees, S. C., Van der Ent, S., and Pieterse, C. M. 2008. Plant immune responses triggered by beneficial microbes. Curr. Opin. Plant Biol. 11: 443-448.

Wibberg, D., Jelonek, L., Rupp, O., Hennig, M., Eikmeyer, F., Goesmann, A., Hartmann, A., Borriss, R., Grosch, R., Pühler, A., and Schlüter, A.

2013. Establishment and interpretation of the genome sequence of the phytopathogenic fungus Rhizoctonia solani AG1-IB isolate 7/3/14 J. Biotechnol. 167:142-155.

Wibberg, D., Jelonek, L., Rupp, O., Kröber, M., Goesmann, A., Grosch, R., Pühler, A., and Schlüter, A. 2014. Transcriptome analysis of the phytopathogenic fungus Rhizoctonia solani AG1-IB 7/3/14 applying high-throughput sequencing of expressed sequence tags (ESTs). Fungal Biol. 118:800-813.

Zeriouh, H., de Vicente, A., Pérez-García, A., and Romero, D. 2014 Surfactin triggers biofilm formation of Bacillus subtilis in melon phylloplane and contributes to the biocontrol activity. Environ. Microbiol. 16:2196-2211.

\section{AUTHOR-RECOMMENDED INTERNET RESOURCES}

National Center for Biotechnology Information BioProject database: www.ncbi.nlm.nih.gov/bioproject

NCBI dEST database: http://www.ncbi.nlm.nih.gov/dbEST 